\title{
Contribution to the translation and validation of the Self-Administered Amyotrophic Lateral Sclerosis Functional Rating Scale - Revised, for European Portuguese
}

\author{
Maria da Assunção Coelho de Matos ${ }^{1}$, Isabel Maria Monteiro da Costa ${ }^{1}$, Raquel Portinha ${ }^{1}$, \\ Beatriz Afonso ${ }^{1}$, Katia Barbosa ${ }^{1}$, Carla Sofia Gouveia ${ }^{2}$, and Pedro Miguel Sa-Couto ${ }^{3}$ \\ ${ }^{1}$ University of Aveiro \\ ${ }^{2}$ Centro Hospitalar Tondela Viseu EPE \\ ${ }^{3}$ University of Aveiro Department of Mathematics
}

May 5, 2020

\begin{abstract}
Objective: To contribute to the validation of the self-administered ALSFRS-R - European Portuguese version (ALSFRS-R: EP), and to analyse its reliability in order to enable its use by ALS patients in Portugal. Methods: The study was developed in 3 phases. Phase 1: Translation and cultural adaptation of the self-administered ALFRS-R; Phase 2: Content validation by study participants; Phase 3: Analysis of internal consistency and test - retest reliability. Results: According to a panel of experts $(\mathrm{N}=6)$, a CVI of $100 \%$ were obtained for all ALSFRS-R: EP items. A sample of 18 people with ALS (13 male) fulfilled the test and evaluated its items regarding its clarity, comprehension, difficulty and relevance, obtaining values with an average between 8.6 and 8.9, 8.7 and 8.9, 8.5 and 8.8, and 8.5 and 8.9, respectively. The instrument total score and its subscales presented good internal consistency (Cronbach's $\alpha$ : from 0.72 to 0.92 in the test; from 0.70 to 0.95 in the retest) and reliability (Kendall tau: from 0.575 to 0.990). Considering the scale total score for the test, no statistical differences were observed between females and males nor between bulbar ALS and medullar ALS. The correlation between the total score and age showed to be significant and negative (-0.53). Conclusions: The Self-Administered ALSFRS-R: EP version was successfully translated, validated, and presented good to excellent reliability results. It will allow its use by Portuguese ALS patients and enabling their health professionals to monitor the disease progression at home.
\end{abstract}

\section{Hosted file}

Main text file.doc available at https://authorea.com/users/303508/articles/433683contribution-to-the-translation-and-validation-of-the-self-administered-amyotrophiclateral-sclerosis-functional-rating-scale-revised-for-european-portuguese

\section{Hosted file}

ALSFRS-R Figure.doc available at https://authorea.com/users/303508/articles/433683contribution-to-the-translation-and-validation-of-the-self-administered-amyotrophiclateral-sclerosis-functional-rating-scale-revised-for-european-portuguese

\section{Hosted file}

Table 1.doc available at https://authorea.com/users/303508/articles/433683-contribution-tothe-translation-and-validation-of-the-self-administered-amyotrophic-lateral-sclerosisfunctional-rating-scale-revised-for-european-portuguese 


\section{Hosted file}

Table 2.doc available at https://authorea.com/users/303508/articles/433683-contribution-tothe-translation-and-validation-of-the-self-administered-amyotrophic-lateral-sclerosisfunctional-rating-scale-revised-for-european-portuguese

\section{Hosted file}

Table 3.doc available at https://authorea.com/users/303508/articles/433683-contribution-tothe-translation-and-validation-of-the-self-administered-amyotrophic-lateral-sclerosisfunctional-rating-scale-revised-for-european-portuguese

\section{Hosted file}

Table 4.doc available at https://authorea.com/users/303508/articles/433683-contribution-tothe-translation-and-validation-of-the-self-administered-amyotrophic-lateral-sclerosisfunctional-rating-scale-revised-for-european-portuguese 